\title{
Simulation of Horizontal and Vertical Waterflooding in a Homogeneous Reservoir using ECLIPSE
}

\author{
Ambrose A. Ugwu Britt M.E Moldestad \\ Department of Process, Energy and Environmental Technology, University College of Southeast Norway, \\ britt.moldestad@usn. no
}

\begin{abstract}
Among the recent deents to improve oil and gas recovery, water injection called waterflooding could be promising. The objective of this work is to ascertain the optimal water injection arrangement between vertical and horizontal waterflooding using ECLIPSE Reservoir simulation software. Within this work, analyses of oil production rate, water cut, reservoir pressure drop, accumulated oil production and recovery factor were made between horizontal and vertical waterflooding in a homogeneous reservoir. Result shows that horizontal waterflooding could be effective if water breakthrough is delayed. The increase in oil recovery achieved through this method varied between $6 \%$ and $36 \%$ while the delay in breakthrough varied between 459 days and 1362 days. This work also predicts production performance for ten years which would be useful for dynamic optimization of waterflooding. However, reservoir heterogeneity would introduce geological uncertainty, which could bring mismatch between the simulated case and a real case.
\end{abstract}

Keywords: ECLIPSE, IOR, waterflooding, reservoir

\section{Introduction}

Waterflooding is a secondary method of oil recovery where water is injected into the reservoir with the aim to increase the pressure and thereby increasing oil production (Binder et al., 1956). Waterflooding was first practiced for pressure maintenance after primary depletion and has since become the most widely adopted IOR technique (Morrow and Buckley, 2011). It is now commonly applied at the beginning of reservoir development(Morrow and Buckley, 2011).

With water injection, the reservoir pressure is sustained and oil is pushed towards the production well. The oil-water front progresses toward the production well until water breaks through into the production stream. With the increasing water production, the oil production rate diminishes, until the time when the recovery is no longer profitable and the production is brought to an end (Van Essen et al, 2006). Up to 35\%
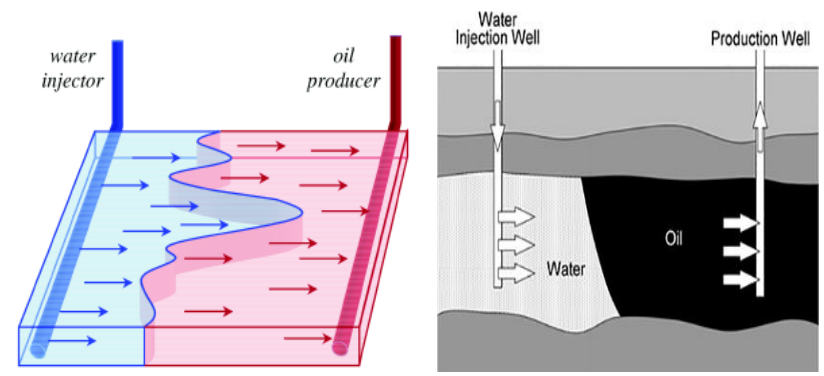

Figure 1. Typical Horizontal and Vertical flooding arrangements (Van Essen et al, 2006): Left (Horizontal waterflooding), Right (Vertical waterflooding).

oil recovery could be achieved economically through waterflooding (Van Essen et al, 2006). Figure1 depicts a typical horizontal and vertical waterflooding arrangement respectively.

Water can be injected through a vertical or a horizontal well. Determining the optimal position and orientation of the wells has a potential high economic impact (Bangerth et al, 2006). One major difference between the horizontal and vertical water injection is the water breakthrough behavior. Asheim studied the optimization of vertical well waterflooding processes with fixed well locations (Zandvliet et al, 2008) while Brouwer and Jansen studied the optimization of waterflooding using a horizontal injection (Brouwer et al, 2001). In both cases, delay in water breakthrough improves production rate. Also from literature, it has been shown that water breakthrough can be delayed by changing the position of the injection well profiles (Brouwer et al, 2001). Studies also revealed that the use of horizontal well, delays the water breakthrough and improves the vertical sweep efficiency (Baker, 1998).

In this paper, computational study of waterflooding in a homogenous reservoir was treated under 6 sections. Sections 1 and 2 deal with the introduction and the theory of waterflooding. Section 3 describes the ECLIPSE mathematical model used in the simulations while Section 4 presents the reservoir model used for the simulations. The simulated results were compared between horizontal and vertical waterflooding in Section 5 with distinct conclusions are in Section 6. 


\section{Theory}

The principal reason for waterflooding is to increase the oil production rate and improve oil recovery. This is achieved through voidage replacement to support the reservoir pressure and sweep or displace oil from the reservoir towards the production well (SPE, 2014). The efficiency of such displacement depends on many factors like oil viscosity, density and rock characteristics. Reservoir screening is necessary for the technical and economic success of waterflooding.

\subsection{Residual Oil Saturation}

Residual oil saturation and connate water saturation are very important numbers in waterflooding. The connate water saturation is saturation is the lowest water saturation found in situ and determines how much oil is available initially, while the residual oil saturation indicates how much of the original oil in place (OOIP) will remain in the pores after sweeping the reservoir with injected water (SPE, 2014). Equation (1) represents the unit-displacement efficiency with the condition that the oil formation volume factor is the same at the start and the end of the waterflooding (SPE, 2014):

$$
\begin{gathered}
E_{D}=1-\frac{S_{\text {orw }}}{S_{o i}} \\
S_{\text {orw }}=1-S_{\mathrm{wc}}
\end{gathered}
$$

where $E_{D}$ is the unit displacement efficiency $S_{o i}$ is the initial oil saturation, $S_{\text {orw }}$ is the residual oil saturation and $S_{\mathrm{wc}}$ is the connate water saturation.

\subsection{Wettability}

The wettability of a reservoir rock can be defined as the tendency of a fluid to spread on, or to adhere to a solid surface in the presence of another immiscible fluid (Owens and Archer, 1971). In an oil- water system it is a measure of the preference the rock has for either oil or water (Anderson, 1987). Changes in wettability influence the capillary pressure, irreducible water saturation, relative permeability and water flood behavior (Anderson, 1987). Maximum oil production rate by waterflooding is normally achieved at water-wet conditions shortly after water breakthrough (Jadhunandan and Morrow, 1995).

\subsection{Capillary Pressure}

Capillary pressure is the pressure difference existing across the interface separating two immiscible fluids in porous media. Capillary pressure determines the amount of recoverable oil for waterflooding applications through imbibition process for water wet reservoir (SPE, 2014).

\subsection{Relative Permeability}

The Relative permeability is the ratio of the effective permeability to the absolute permeability of each phase. It is expressed for a specific saturation of the phases as

$$
\mathrm{k}_{\mathrm{r}, \mathrm{i}}=\frac{\mathrm{k}_{\mathrm{i}}}{\mathrm{k}}
$$

where is the phase relative permeability, $\mathrm{k}$ is the total effective permeability and is the phase effective permeability.

Relative permeability affects the unit displacement efficiency and how much of the OOIP will be recovered before the waterflooding economic limit is reached. When the interfacial tension between oil and gas phases decreases, the relative permeability values change (AlWahaibi et al., 2006), which influences the oil and gas recovery as well as the reservoir pressure. Figure 2 shows the plot of relative permeability curve used for the simulation.

\subsection{Mobility}

Mobility, $\lambda$ is described as the ratio between the endpoint effective permeability and the fluid viscosity, $\mu$. It shows how easy the fluid is flowing through a porous medium (Ydstebø, 2013). Mobility ratio, M, plays an important role during waterflooding. It can be defined as the ratio between the mobility of the displacing fluid (water) and the displaced fluid (oil) (Ydstebø, 2013):

$$
\mathrm{M}=\frac{\lambda_{\text {(displacing) }}}{\lambda_{\text {(displaced) }}}=\frac{\mathrm{K}_{\mathrm{r}_{(\text {displacing })}} \mu_{(\text {displaced })}}{\mathrm{K}_{\mathrm{r}(\text { displaced }) . \mu_{(\text {displacing })}}}
$$

where $\mathrm{M}$ is the mobility ratio, $\lambda$ is the mobility, $\mathrm{kr}$ is the relative permeability, $\mu$ is the viscosity. The subscripts displacing and displaced represent the displacing phase and the displaced phases respectively.

Mobility ratio is considered to be either favorable if the value of (4) is less than or equal to unity or unfavorable if the value is greater than unity (SPE, 2014). Favorable mobility ratio means that the displaced phase (oil) can move more quickly than the displacing phase (water) through the reservoir rock.

\section{Computational Model}

ECLIPSE Reservoir simulation is a form of numerical modeling used to quantify and interpret physical phenomena with the ability to predict future performance. The process involves dividing the reservoir into several discrete units in three dimensions, and modeling the progression of reservoir and fluid properties through space and time in a series of discrete steps (Schlumberger, 2013). Equations (5-11) are solved for each cell and each time step which are a combination of the material balance equation and Darcy's law (Schlumberger, 2008). 
i. Darcy's law (without gravity term) is expressed as

$$
\mathrm{q}=-\frac{\mathrm{K}}{\mu} \nabla \mathrm{P}
$$

where $\mathrm{q}$ is the flux, $\mathrm{k}$ is the permeability; $\mu$ is the viscosity and is the pressure gradient.

ii. Material Balance is expressed as

$$
-\nabla \cdot M=\frac{\partial}{\partial t}(\varnothing \rho)+Q
$$

where $\mathrm{M}$ is the mobility ratio, $\varnothing$ is the porosity, $\rho$ is density and $Q$ is volume flow rate. Here, mass flux is considered as the sum of the accumulation and Injection/Production.

iii. Simulator Flow Equation (with gravity term) is given in (7).

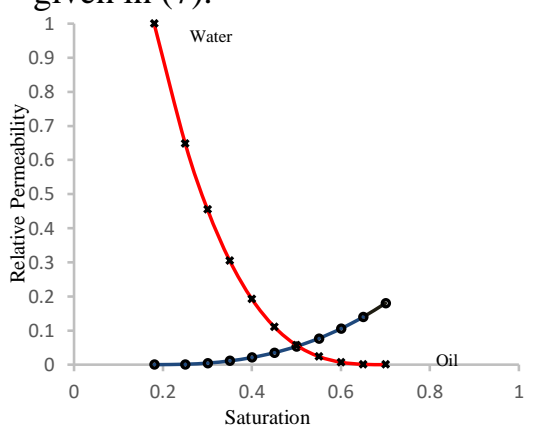

Figure 2. Relative Permeability curve (water-wetted).

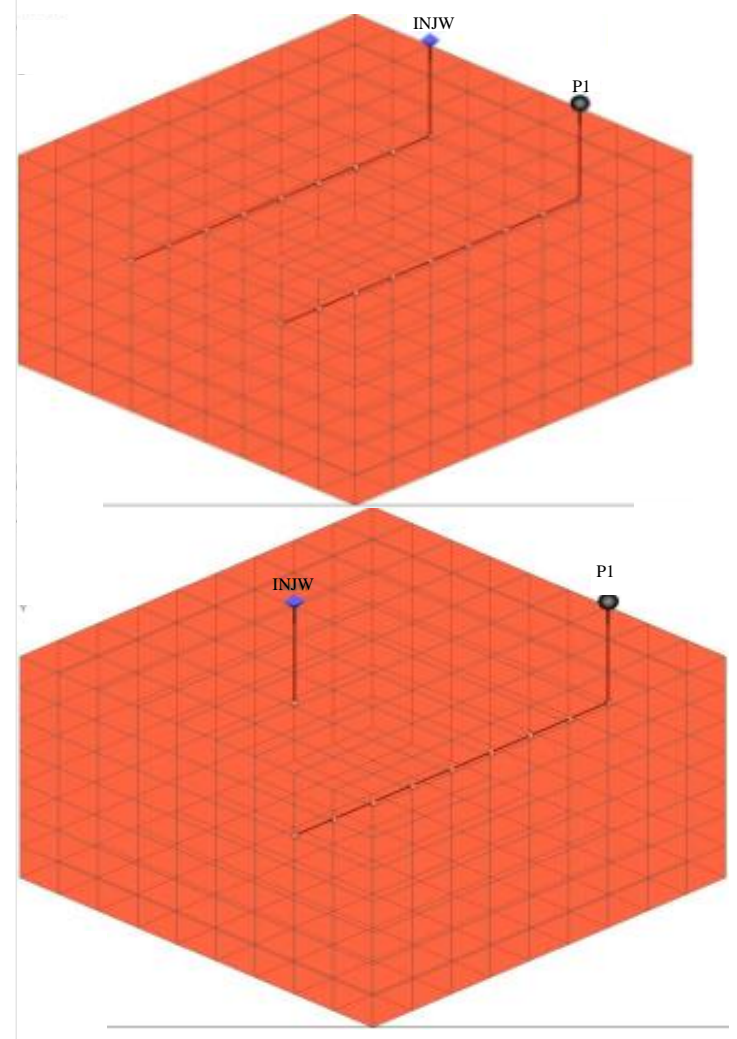

Figure 3. Reservoir Geometry (3D): up(horizontal injection), down(vertical injection).

$$
\begin{aligned}
& \nabla \cdot[\lambda(\nabla P-\gamma \nabla Z)]=\frac{\partial}{\partial t}\left(\frac{\emptyset}{\beta}\right)+\frac{Q}{\rho} \\
& \lambda=-\frac{K}{\mu \beta}
\end{aligned}
$$

where $\mathrm{M}$ is mobility, $\mathrm{t}$ is time, $\beta$ is momentum transfer coefficient, $\gamma$ is relative gravity and $\mathrm{Z}$ is vertical position.

iv. Well Model is expressed as:

$$
\begin{gathered}
q_{p, j}=T_{w j} M_{p, j}\left(P_{j}-P_{w}-H_{w j}\right) \\
M_{o, j}=\frac{K_{0, j}}{B_{0, j} \cdot \mu_{0, j}}+R_{v} \frac{K_{g, j}}{B_{g, j} \cdot \mu_{g, j}} \\
M_{g, j}=\frac{K_{g, j}}{B_{g, j} \cdot \mu_{g, j}}+R_{s} \frac{K_{0, j}}{B_{0, j} \cdot \mu_{0, j}}
\end{gathered}
$$

where $\mathrm{T}$ is the transmissibility, $\mathrm{P}$ is the pressure, $\mathrm{H}$ is the pressure head, $\mathrm{B}$ is the formation volume factor, $R_{s}$ is the gas-oil ratio and $R_{v}$ is the oil-gas ratio. The subscripts $p$ is phase, $j$ is connection, $\mathrm{w}$ is well, $\mathrm{o}$ is oil and $\mathrm{g}$ is gas.

\section{ECLIPSE Simulation}

Simulations were carried out for 10 years by injecting water at a constant rate through a horizontal and a vertical well respectively. In both cases, water was injected at the same depth as the production well. Also the same lateral distance was maintained between the injection well and the production for both cases. Different simulations were performed by varying injection rate from $200 \mathrm{~m}^{3} /$ day to $2,500 \mathrm{~m}^{3} /$ day for each case. A base case without water injection was considered for reference.

\subsection{Geometry}

Rectangular reservoir geometry was considered with the dimension $900 \mathrm{~m} \times 900 \mathrm{~m} \times 70 \mathrm{~m}$. Figure 3 shows the reservoir geometry for the horizontal and the vertical water injection used in the simulation. The horizontal production (P1) and injection (INJW) wells are $800 \mathrm{~m}$ long respectively while the length of the vertical injection well (INJW) is $40 \mathrm{~m}$.

\subsection{Reservoir Conditions}

The reservoir is homogeneous and consists of waterwetted rock. Although the reservoir fluid consists of live black oil, gas production was not considered for simplicity. The composition of oil components is assumed to be constant relative to pressure and time. It is also assumed that the reservoir fluid is Newtonian and that Darcy's law applies. Also, the production of light oil in a moderate permeability zone is of interest. The reservoir conditions are summarized in Table 1. 


\subsection{Initial Conditions}

Initially, the reservoir is assumed to be in hydrostatic equilibrium consisting of only oil. It is also desired to have the reservoir pressure above the bubble point to avoid gas production. Initial drawdown pressure of 10bar is also desired. Table 2 shows the initial conditions considered for the simulation.

\section{Results and Discussion}

In this simulation, analysis of the oil production rate, water cut, reservoir pressure, accumulated oil production and recovery factor were made for the horizontal and vertical waterflooding. A base case without water injection was also considered as reference.

\section{Results and Discussion}

In this simulation, analysis of the oil production rate, water cut, reservoir pressure, accumulated oil production and recovery factor were made for the horizontal and vertical waterflooding. A base case

Table 1. Reservoir Conditions.

\begin{tabular}{|l|l|l|}
\hline Parameter & Value & Unit \\
\hline Components & Oil, water, gas & - \\
\hline Wettability & Water-wetted & - \\
\hline Porosity & 0.25 & - \\
\hline X Permeability & 1 & Darcy \\
\hline Y Permeability & 1 & Darcy \\
\hline Z Permeability & 0.1 & Darcy \\
\hline Rock compressibility & $5.0 \mathrm{E}-5 @ 10 \mathrm{Bar}$ & $/$ Bar \\
\hline Oil gravity & 35 & ${ }^{\circ} \mathrm{Api}$ \\
\hline Residual oil saturation & 0.3 & - \\
\hline Oil viscosity & $3 @ 320 \mathrm{Bar}$ & $\mathrm{cP}$ \\
\hline Water Density & 1000 & $\mathrm{~kg} / \mathrm{m}^{3}$ \\
\hline Water viscosity & 0.5 & $\mathrm{cP}$ \\
\hline Connate water saturation & 0.2 & - \\
\hline Gas density & 1 & $\mathrm{~kg} / \mathrm{m}^{3}$ \\
\hline Total simulation time & 3653 & $\mathrm{days}$ \\
\hline No of Grids & $567(9 \times 9 \times 7)$ & - \\
\hline
\end{tabular}

Table 2. Initial Conditions

\begin{tabular}{|l|l|l|}
\hline Initial condition & Value & Unit \\
\hline Reservoir pressure & 320 & Bar \\
\hline Bottomhole pressure & 310 & Bar \\
\hline Bubble point pressure & 182 & Bar \\
\hline Oil saturation & 1 & - \\
\hline Water saturation & 0 & - \\
\hline Gas saturation & 0 & - \\
\hline
\end{tabular}

\subsection{Production Rate Trend}

Figure 4 shows the oil production rate for horizontal and vertical water injection respectively. The plot shows that horizontal waterflooding maintains higher oil production rate for a longer period until water breaks through. After water breakthrough, the production rate drops more for horizontal waterflooding than the vertical case. This may be attributed to rapid water production in all zones in the horizontal waterflooding case, whereas for the vertical case water breakthrough occurs first in a few zones. The production rate for the base case is very low compared to the cases with waterflooding. This is in agreement that waterflooding improve the oil production rate (Morrow and Buckley, 2011)

\subsection{Reservoir Pressure Trend}

Figure 5 shows the simulated reservoir pressure trend. For injection rates less than $1500 \mathrm{~m}^{3} /$ day, the pressure drop with horizontal injection is between $4 \%$ and $6 \%$ less than for the vertical case. For injection rates between $1500 \mathrm{~m}^{3} /$ day and $2500 \mathrm{~m}^{3} /$ day, the pressure drop is between $9 \%$ and $14 \%$ less with horizontal flooding compared to vertical flooding.

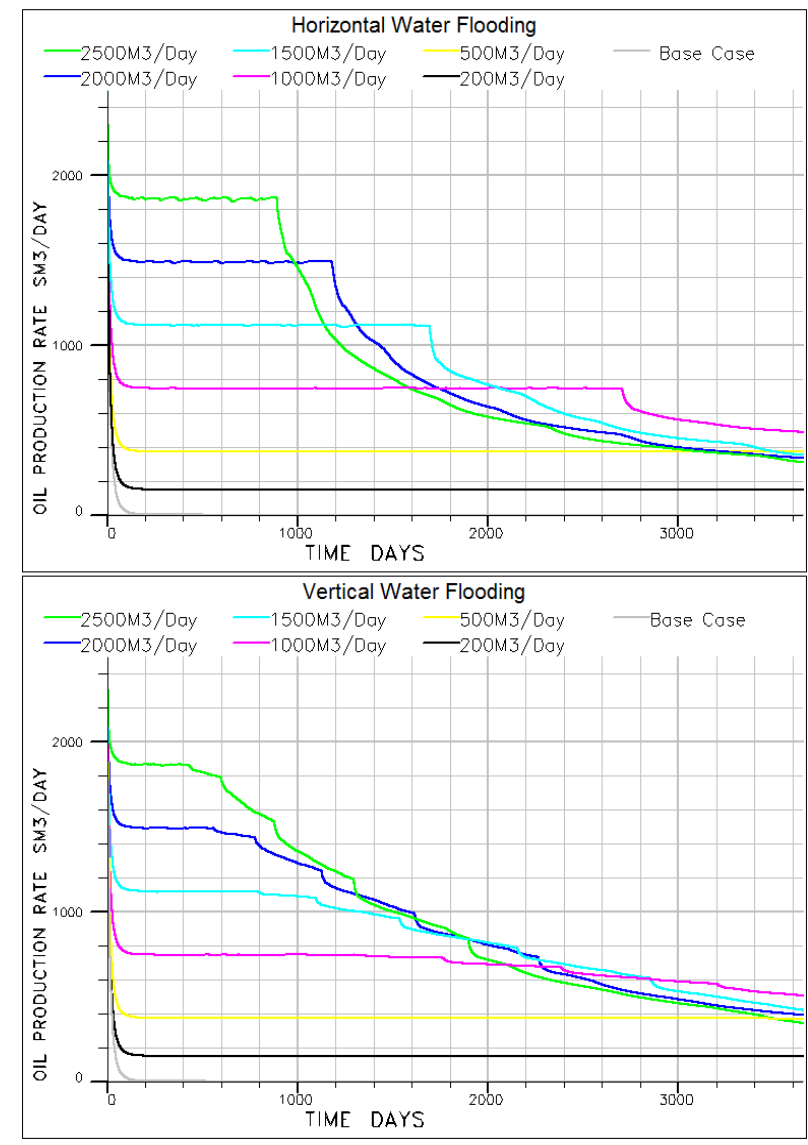

Figure 4. Plot of oil production rate against time: upper plot(horizontal), lower plot(vertical). 


\subsection{Watercut Trend}

The water cut trend is shown in Figure 6. It is observed that water breakthrough is delayed between 459 days and 1362 days with horizontal case compared with the vertical case. Despite of the late water breakthrough, the water cut after 3653 days is higher using horizontal flooding in all the cases.

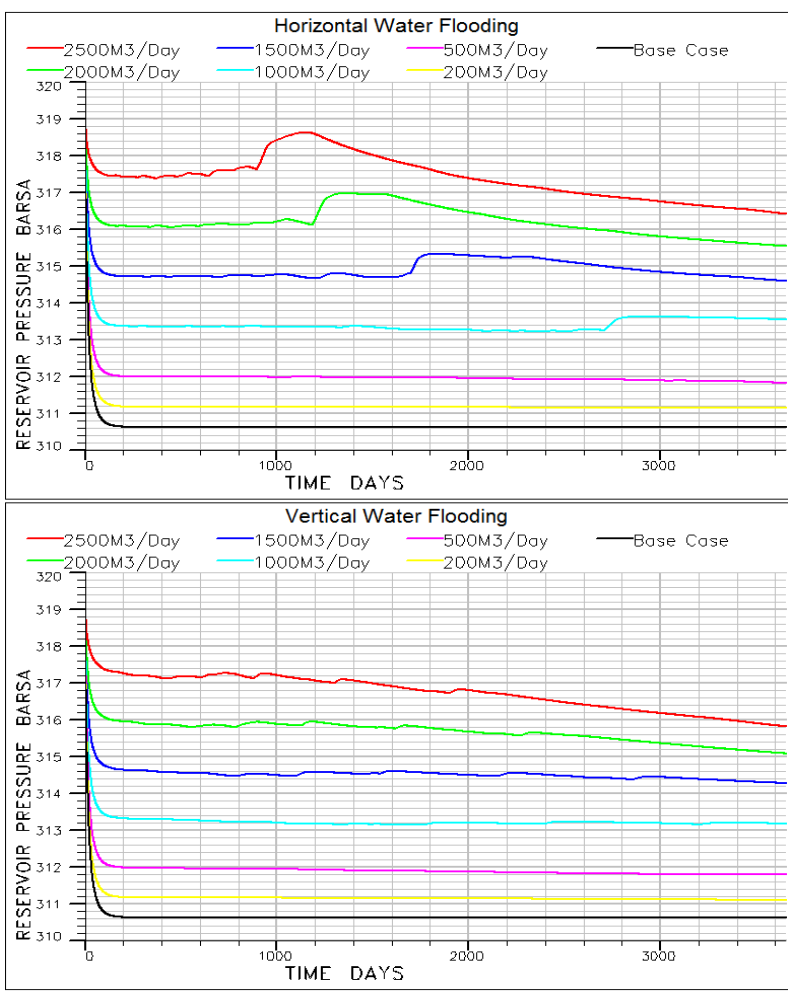

Figure 5. Plot of reservoir pressure against time: upper plot(horizontal), lower plot(vertical ).

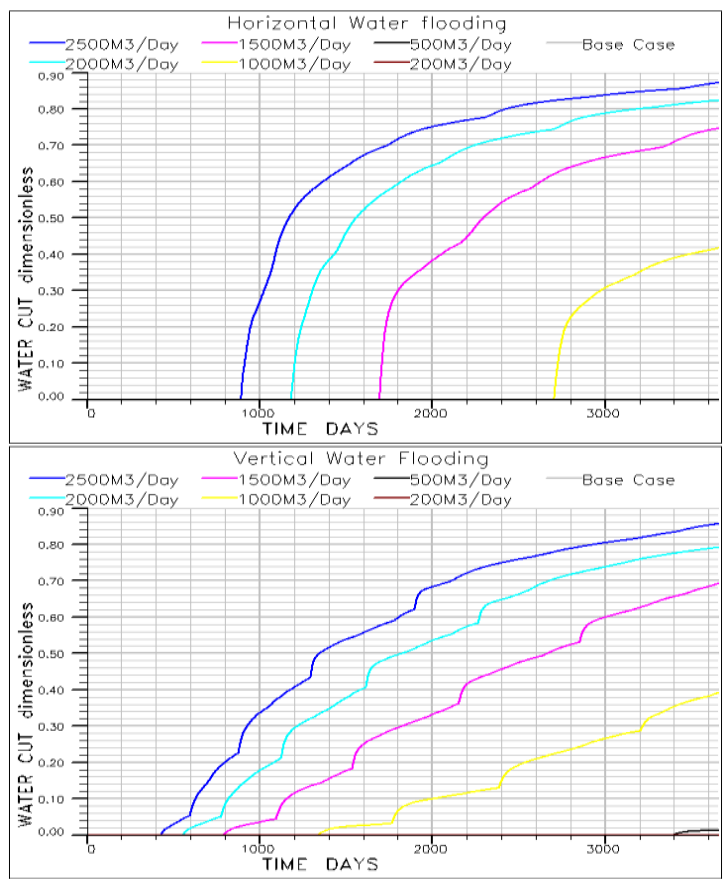

Figure 6. Plot of watercut against time: upper plot(horizontal injection), lower plot(vertical injection).

\subsection{Accumulated Oil Production}

Figure 7 shows the accumulated oil production trend. The plot shows that the accumulated oil production with horizontal flooding is higher for injection rates less than $1500 \mathrm{~m}^{3} /$ day due to lower pressure drop in the reservoir. For injection rates greater than $1500 \mathrm{~m}^{3} /$ day, accumulated oil production using horizontal flooding is less than for vertical flooding. This may be attributed to the rapid water production in horizontal flooding as opposed to vertical flooding.

The plot of the recovery factor against injection rate shown in Figure 8 indicates that the recovery factor with horizontal flooding is less than for vertical flooding for injection rates greater than $1500 \mathrm{~m}^{3} / \mathrm{day}$. This may be due to rapid water breakthrough.

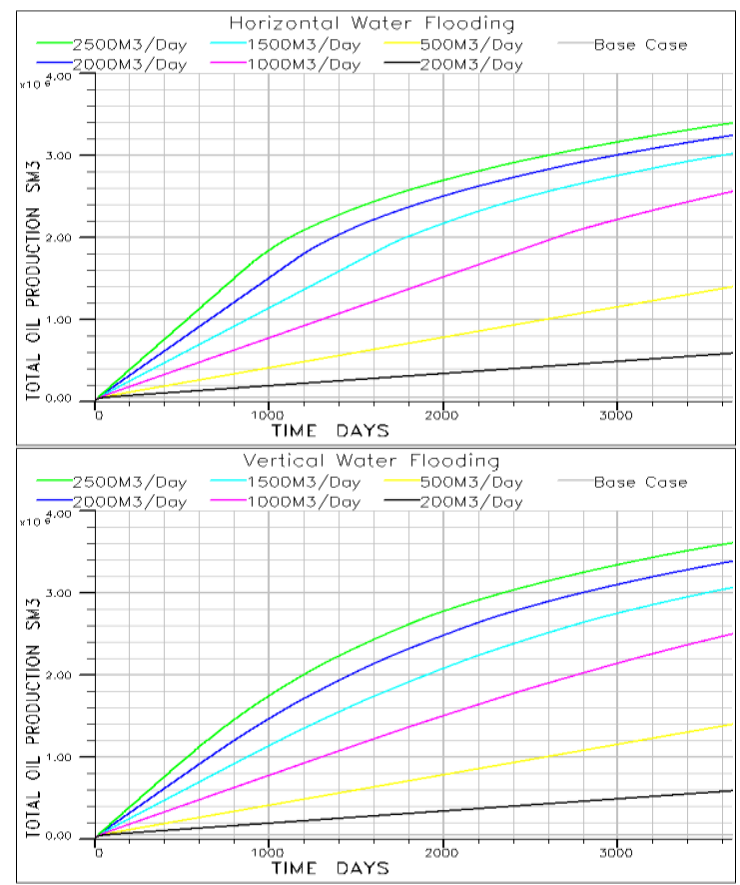

Figure 7. Accumulated oil production against time: upper plot(horizontal), lower plot(vertical).

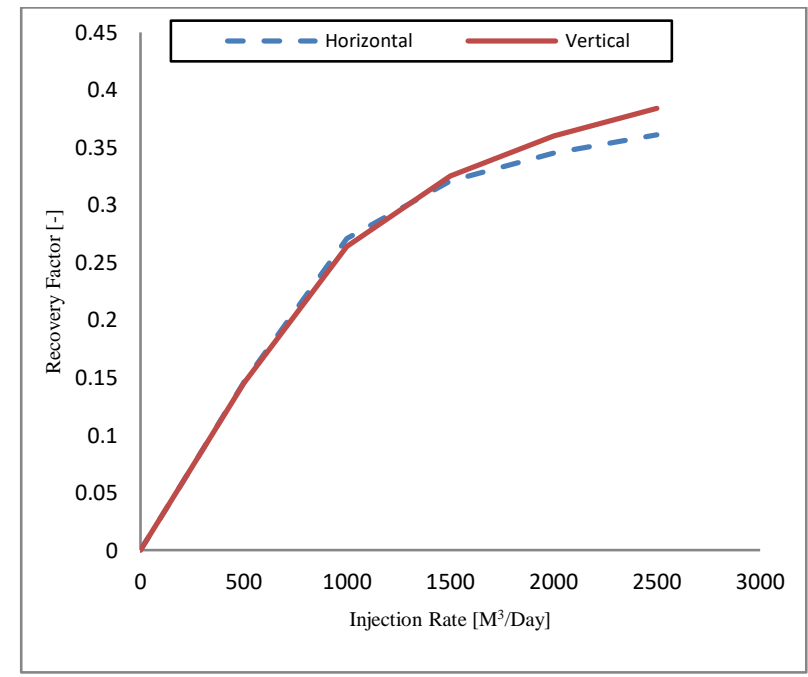

Figure 8. Plot of recovery factor against injection rate. 


\subsection{Oil Saturation Distribution}

The case for water injection at $1500 \mathrm{~m}^{3} /$ day is chosen to illustrate how oil saturation is distributed in the reservoir over time for horizontal and vertical water injection respectively. Initially, the oil saturation is 1 for both cases as shown in Figure 3.

Figure 9 shows the oil saturation distribution for horizontal injection after ten years. It can be seen that about $32 \%$ oil recovery was achieved through waterflooding. Figure 10 shows the oil saturation distribution for vertical injection after ten years. About $33 \%$ oil recovery was achieved through waterflooding.

\subsection{Oil-Water Front Progression}

The case for water injection at $1500 \mathrm{~m}^{3} /$ day is used to illustrate how water displaces oil and sweeps oil towards the production well in the reservoir. Figure 11 shows the plan view of the oil-water front progression for the horizontal and vertical water injection after two years. Figure 10 shows the oil saturation distribution for vertical injection after ten years. About 33\% oil recovery was achieved through waterflooding.

\subsection{Oil-Water Front Progression}

The case for water injection at $1500 \mathrm{~m}^{3} /$ day is used to illustrate how water displaces oil and sweeps oil towards the production well in the reservoir. Figure 11 shows the plan view of the oil-water front progression for the horizontal and vertical water injection after two years.

The oil-water front progression after ten years is shown in Figure 12. From the plot, it can be seen that the oil saturation reduced due to more sweep by water injection. In general, result shows that oil-water front progresses laterally for horizontal flooding and radially for vertical flooding.

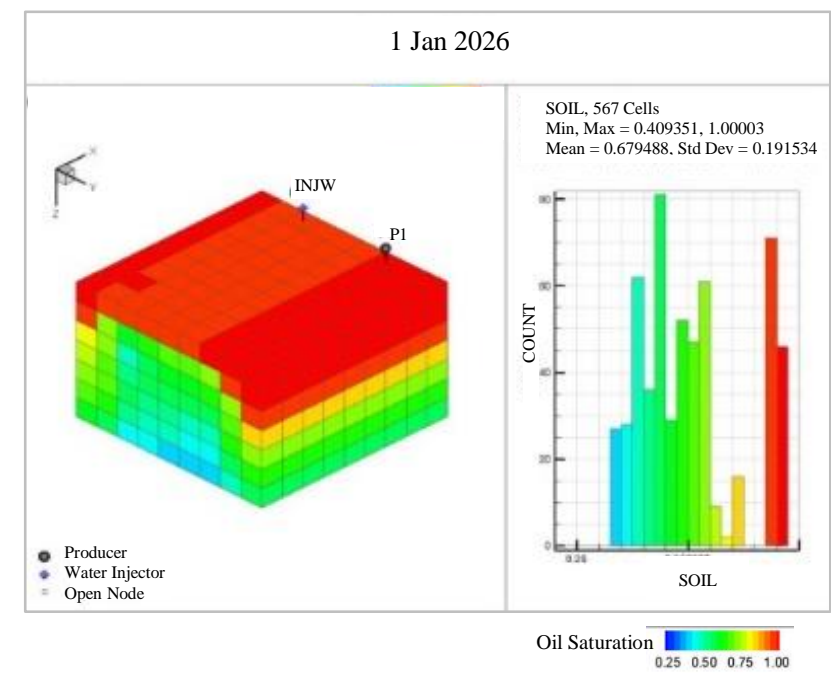

Figure 9. Oil saturation distribution for horizontal injection after 10 years.

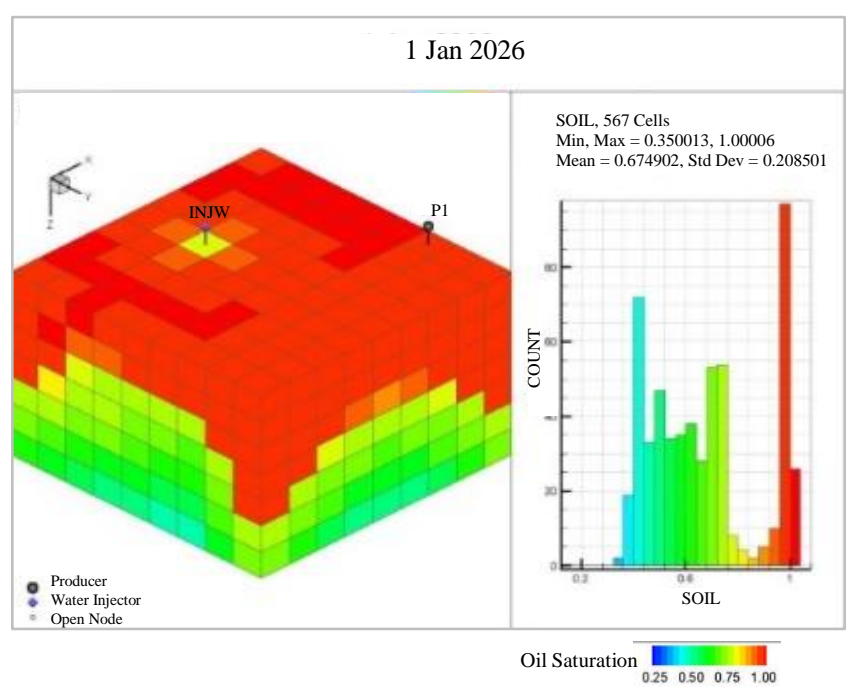

Figure 10. Oil saturation distribution for vertical injection after 10 years.

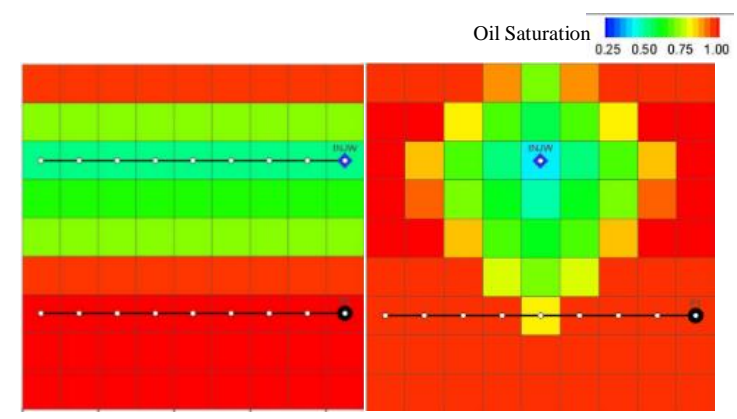

Figure 11. Oil-water front progression after 2 years: left(horizontal injection), right(vertical injection).

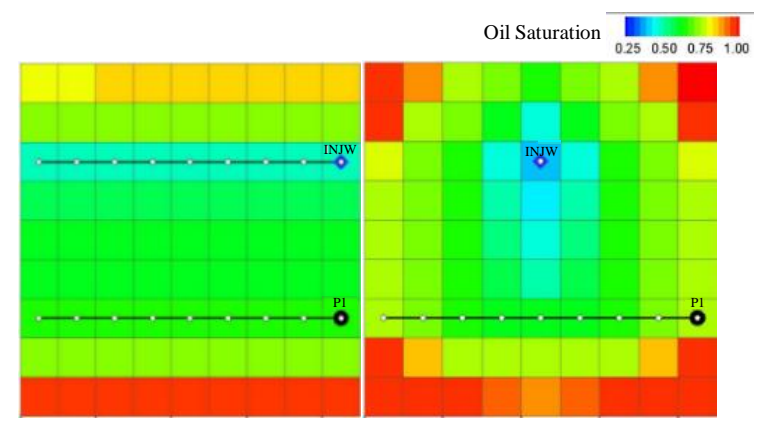

Figure 12. Water front progression after 10 years: left (horizontal injection) right (vertical injection).

\section{Conclusions}

This paper compares oil production rate, water cut, reservoir pressure drop, accumulated oil production and recovery factor between horizontal and vertical waterflooding in a homogeneous reservoir. The simulation was performed over ten years (3653 days) using ECLIPSE Reservoir simulator.

In all cases, result shows that oil production with water injection is higher compared with the base case. With this, it would be preferred to apply waterflooding for oil recovery in depleted reservoirs to the use of primary methods. Result also shows that horizontal 
waterflooding maintains higher oil production rate for a longer period until water breakthrough. It is also observed that water breakthrough is earlier and water production increases gently with vertical flooding unlike the horizontal case where the water breakthrough comes late but water production increases rapidly with time.

With this, it would be preferred to apply waterflooding for oil recovery in depleted reservoirs to the use of primary methods. Result also shows that horizontal waterflooding maintains higher oil production rate for a longer period until water breakthrough. It is also observed that water breakthrough is earlier and water production increases gently with vertical flooding unlike the horizontal case where the water breakthrough comes late but water production increases rapidly with time.

The pressure drop is higher with vertical flooding in all cases compared with the horizontal flooding. This may be due to higher frictional pressure drop and the effect of gravity. More difference in pressure drop is noticed between horizontal and vertical flooding with increase in injection rate.

Despite higher reservoir pressure and delay in water breakthrough, horizontal flooding accounts for less oil recovery due to rapid water production. With the implementation of inflow control device to reduce water production, oil recovery through horizontal waterflooding would be optimal and more effective than vertical waterflooding.

\section{References}

Y. AL-Wahaibi, C. Grattoni and A. Muggeridge, A. Drainage and imbibition relative permeabilities at near miscible conditions. Journal of Petroleum Science and Engineering, 53: 239-253, 2006.

W. G. Anderson. Wettability literature survey part 5: the effects of wettability on relative permeability. Journal of Petroleum Technology, 39(11): 1,453-451,468, 1987.

R. Baker. Reservoir management for waterfloods-Part II. Journal of Canadian Petroleum Technology, 37(1): 300325, 1998.

W. Bangerth, H. Klie, M. Wheeler, P. Stoffa and M. Sen. Optimization Algorithms for The Reservoir Oil Well Placement Problem. Computational Geosciences, 10(3): 303-319, 2006.

J. G. G. Binder, R. C. West and K. H. Andresen. Water flooding secondary recovery method. Google Patents, 1956.

D. Brouwer, J. Jansen, S. Van Der Starre, C. Van Kruijsdijk and C. Berentsen. Recovery Increase through Water Flooding with Smart Well Technology. In Proceedings of the SPE European Formation Damage Conference. Society of Petroleum Engineers, 2001.

P. Jadhunandan and N. R. Morrow. Effect of Wettability on Waterflood Recovery for Crude-Oil/Brine/Rock Systems. SPE Journal Reservoir Engineering, 10(1): 40-46, 1995.
N. Morrow and J. Buckley. Improved Oil Recovery by LowSalinity Waterflooding. Journal of Petroleum Technology, 63(5): 106-112, 2011.

W. Owens and D. Archer. The effect of rock wettability on oil-water relative permeability relationships. Journal of Petroleum Technology, 23(7): 873-878, 1971.

Schlumberger Limited. ECLIPSE Blackoil Reservoir Simulation, 2008.

Schlumberger Limited. ECLIPSE Reservoir Simulation Software - Technical Description, 2013.

SPE (Society of Petroleum Engineers). Microscopic Efficiency of Waterflooding. Available via http://petrowiki.org/Waterflooding [Accessed March 5, 2016].

G. Van Essen, M. Zandvliet, P. Van Den Hof, O. Bosgra and J. Jansen. Robust optimization of oil reservoir flooding. In Proceedings of the IEEE International Conference on Control Applications, 699-704, 2006.

T. YDSTEBØ. Enhanced Oil Recovery by $\mathrm{CO}_{2}$ and $\mathrm{CO}_{2}-$ Foam in Fractured Carbonates. The University of Bergen, 2013.

M. Zandvliet, M. Handels, G. Van Essen, R. Brouwer and J. D. Jansen. Adjoint-based well-placement optimization under production constraints. SPE Journal, 13(4): 392-399, 2008. 